\title{
YOUNG DRIVERS
}

\section{Legislative advocacy is key to addressing teen driving deaths}

\section{J S Gillan}

Injury Prevention 2006;12(Suppl I):i44-i48. doi: 10.1136/ip.2006.012880

The increased crash risk of young, novice drivers, especially in their teenage years, has been a growing concern at both the state and federal levels. Teenage drivers are involved in fatal crashes at more than double the rate of the rest of the population per 100000 licensed drivers. The best way of stemming these losses is to enact laws adopting graduated licensure systems that restrict young, novice drivers to conditions that reduce crash risk exposure when they first operate motor vehicles and to educate the public on the need for this legislation. Legislated teenage driving restrictions involve night-time vehicle driving restrictions, prohibitions on other teenage passengers, and the required presence of supervising adults. These restrictions are relaxed as teenage drivers successfully progress through initial and intermediate stages of graduated licensure before being granted unrestricted driver licenses. Unfortunately, many states have incomplete graduated licensing systems that need further legislative action to raise them to the desirable three-stage system that has been shown repeatedly to produce the greatest safety benefits. These state efforts should be buttressed by federal legislation that has proved to be crucial in allied driver behavioral concerns. Because reducing crash risk involves other strategies, stringent enforcement of primary seat belt laws as well as improved motor vehicle crash avoidance capabilities and crashworthiness must accompany efforts to reduce young driver crash risk.

Accepted 27 April 2006

b the area of driver related safety issues, specifically behavioral changes that can lead to significant improvements in safety, experience has shown that neither education nor training are themselves sufficient to assure long term, socially desired changes in behavior. Advocates for Highway and Auto Safety, an organization dedicated to reducing the harm caused by motor vehicle crashes, pursues policy changes that combine education with legal requirements that are supported by enforcement action. This mix of initiatives appears to have the most powerful salutary impact when it comes to improving behavior of motor vehicle operators in general. Advocates has pursued this combination of measures wherever possible in addressing behavioral issues that affect the safety of drivers and passengers.

Reducing teenage traffic deaths and injuries is a major program priority for Advocates. Efforts have focused on the following actions:

- passing effective graduated driver licensing (GDL) laws and primary seat belt laws in state legislatures and Congress;

- educating legislators and policy leaders about the need for legislative and policy initiatives to address teen driving; and

- improving vehicle safety by promoting stronger federal safety standards.

\section{SCOPE OF THE TEENAGE DRIVING SAFETY PROBLEM}

Motor vehicle crashes are the leading cause of death for 15-20 year olds. ${ }^{1}$ In 2004, 7898 15-20 year old drivers were involved in fatal crashes, 3620 drivers in this age group were killed and an additional 303000 were injured. By any measure, this represents a public health epidemic. ${ }^{2}$

Data show that teenage drivers are overrepresented in motor vehicle crashes, far exceeding their percentage among licensed drivers. Even though teenage drivers as a group drive fewer miles per year than drivers in other age groups, teenage drivers are involved in fatal crashes at more than double the rate of the rest of the population (per 100000 licensed drivers), and their involvement rate in all crashes is more than three times that of the general population of licensed drivers. $^{2}$

A number of factors contribute to this situation. While younger drivers in general tend to have good eyesight, reflexes, and hand-eye coordination, ${ }^{3}$ they frequently lack the experience and good judgment necessary in critical driving situations. Teenage drivers are less likely than adults to accurately perceive danger and more likely to commit driving errors that lead to a crash, such as driving at excessive speeds in the prevailing conditions or overcompensating during sudden maneuvers. ${ }^{45}$ In addition, they have a greater propensity to engage in risk taking behaviors, such as speeding and driving recklessly, compared to other age groups. ${ }^{5}$ Teenage drivers are more likely to be involved in single vehicle crashes and crashes with peers, especially male peers. ${ }^{6}$ Drivers under the age of 20 are also overrepresented in rollover fatalities. ${ }^{72}$ Finally, teenagers are statistically less likely to be wearing seat belts either as drivers or passengers of motor vehicles. ${ }^{8}$ These factors all contribute to teenage drivers having the highest crash and fatality rate of all age groups of drivers, a finding that applies even when the data for male and female teenage drivers are disaggregated.

Abbreviations: GDL, graduated licensing system; MADD, Mothers Against Drunk Driving; NHTSA, National Highway Traffic Safety Administration; SAFETEA-LU, Safe Transportation Equity Act - A Legacy for Users; STANDUP, Safe Teen and Novice Driver Uniform Protection Act of 2005 


\section{APPROACH TO ACHIEVING LEGISLATIVE SUCCESS IN THE US \\ Uniform enactment of strong graduated driver licensing laws}

It has been repeatedly documented that young drivers are at increased risk when there are one or more teen passengers on board and vehicle operation occurs during the higher crash risk hours of darkness, especially on weekends. ${ }^{9}{ }^{10}$ Every state and foreign country that has instituted some version of GDL has experienced success in reducing the frequency of teen driver collisions that occur when teenage drivers are provided unrestricted, full licensure especially when 16 or 17 years of age. In fact, as Thomas Dee and his co-authors pointed out in 2005, no research findings on the effects of GDL in any state or foreign country that has adopted some version of the licensing control on teen driving has failed to find positive effects. ${ }^{11}$

Both federal and state legislative actions requiring GDL, coupled with public education on the benefits of GDL, are necessary to lower teenage driver and teenage occupant crash deaths and injuries. For years, government sponsored slogans and industry public relations campaigns focused on the dangers of drinking and driving did not achieve sustained or consistent declines in the number of annual drunk driving fatalities. When safety groups, particularly Mothers Against Drunk Driving (MADD), changed the focus to enactment of state and federal laws such as the minimum 21 year old drinking age, tougher penalties for impaired driving, reducing the blood alcohol concentration level to $0.08 \%$ in every state, combined with education and enforcement of these laws, drunk driving deaths and injuries began to steadily drop. From 2003 to 2004, national alcohol related motor vehicle crash deaths fell from 12997 to 12 636, a $2.8 \%$ reduction in a single year. ${ }^{12}$ Likewise, alcohol related motor vehicle fatalities fell by $2.9 \%$ from 2002 to $2003 .{ }^{13}$

Similarly, Advocates is working to bring about uniformity in state GDL laws with this two-pronged strategy to accelerate state adoption of laws that have the following four elements:

1. Minimum six-month holding period. During this period an adult licensed driver must supervise a new driver at all times. In a graduated system, an extended learner's period is essential to provide the opportunity for extensive supervised on-road practice in a variety of conditions. The developing consensus is that a minimum of six months is reasonable and necessary. ${ }^{14}$

2. Thirty to 50 hours of supervised driving. A new driver should complete 30-50 hours of behind-the-wheel training with an adult licensed driver. ${ }^{14}$ This again aims to ensure a minimum amount of supervised on-road practice in a variety of conditions.

3. Night-time driving restriction. Under Advocates' optimal GDL program, unsupervised driving should be prohibited from $10 \mathrm{pm}$ to $5 \mathrm{am}$. Night-time driving is especially risky for young beginners and young people in general. ${ }^{15}$

4. Passenger restriction. The number of teenage passengers that should be allowed to accompany a teen driver without adult supervision is one non-familial teenager. ${ }^{16}$ This also is a recommendation of the National Transportation Safety Board, ${ }^{17}$ while others recommend more stringent restrictions. As of March 2006, only the state of Nevada has all four elements of an optimal graduated license law, and 18 states and the District of Columbia have three of the four optimal provisions. There is a patchwork quilt of teenage driving laws across the country, and too many states have too few of these life saving laws. This means that many states have incomplete GDL programs that cannot achieve the benefits of a careful, three-step system of driver licensing.
Each year, Advocates identifies several states that have no components of a comprehensive GDL law or weak laws that need to be upgraded and improved. Working with state and local coalitions, victim advocacy groups, and elected officials, Advocates assists in efforts to promote passage of GDL laws. For example, Advocates' staff works to identify sponsors of GDL legislation, seeks the support of governors, other elected officials and public opinion leaders, attracts media attention by encouraging press events and editorials, and reaches out to victims/survivors of teen driving crashes and helps them to focus their interest and energy in the legislative debate.

Furthermore, in order to push efforts in state legislatures to enact GDL laws, Advocates issues a report in late December or early January before the beginning of most state legislative sessions assessing state progress in adopting about 14 critical highway safety laws in the areas of adult occupant protection, child passenger safety, teen driving, and impaired driving. These are laws which Advocates views as necessary to effectively reduce motor vehicle deaths and injuries. The report, Roadmap to highway safety laws, ${ }^{18}$ evaluates states relative to neighboring states and the rest of the nation in passage of these laws. The evaluation of GDL laws has helped the public, the media, and elected officials identify those states lacking some of the most fundamental laws protecting teens, which in turn has been a catalyst for strengthening GDL laws. Another strategy used by Advocates to encourage states to enact a comprehensive GDL law is the passage of federal legislation. Some of the most important highway safety laws affecting teen driving and uniformly adopted by every state resulted from the United States Congress legislating in order to spur state enactment. These include the national minimum 21 year old drinking age, the zero tolerance blood alcohol concentration (BAC) law for underage drinking and driving, and the $0.08 \%$ BAC law. Uniform state adoption of these three laws resulted from the passage of federal legislation directing states to adopt these lifesaving laws within a specified time period or be penalized millions of dollars in federal highway construction funding.

\section{LESSONS LEARNED \\ Teen driving initiatives, or GDL versus driver education}

Despite the proven track record of GDL, there is still significant opposition to the lifesaving benefits of this rational approach to reducing young driver crash risk, including state legislatures resisting enactment of the GDL concept or of strengthening current programs. These improvements comprise, for example, more restrictions on teen passengers. In some cases, GDL opponents still claim that driver education and training programs can produce the same crash reduction fatality benefits as GDL; however, this view has no real support. Youth driver training courses can teach basic vehicle control skills, but extensive research has shown repeatedly that high school driver education, for example, does not lead to lower crash involvement rates. ${ }^{19}$ This is because many other variables affect young drivers behind the wheel that result in increased crash rates. ${ }^{20}$

Despite driver education, a study conducted for the Commonwealth of Virginia, for example, showed that for use of alcohol and other drugs, speeding, reckless driving, improper driving, high risk behavior, seat belt violations, and administrative violations, the percentage of convicted drivers in their late teens was several times higher than for any other age group. ${ }^{21}$ No study conducted in more than 30 years has shown that teenage driver education effectively reduces either the rate or the severity of young driver crash involvement. ${ }^{19}$

In fact, many authors and researchers point out that young driver education usually enables teenage drivers to gain 
unrestricted licensure at earlier ages when their risk of violations or crashes is much higher than older drivers, while also encouraging them to increase their exposure to crash involvement by driving more miles, longer hours, and more often at night at a younger age..$^{22}$ Even more disturbing are the results of several well known evaluation studies that have shown that intensive driver training courses for novice drivers result in graduates who actually have higher collision rates than those without such training, especially when the subjects are young drivers. ${ }^{24}{ }^{25}$ This research, along with recent work in the area of human brain development, has provided the basis for calls to increase the age of licensure.

Other studies in the US, Canada, Scandinavia, Australia, and New Zealand have also shown that driver education courses produce no long term beneficial advantages in reducing either the frequency or the severity of crash involvements. ${ }^{26}$ The record of research findings is therefore clear that driver education of young teen drivers does not decrease crash rates.

In contrast, GDL systems, especially the programs that contain the most desirable features of a three-step progression in driving privileges, curtailment of night-time driving, and prohibitions on carrying other teens as passengers, ${ }^{9}$ are repeatedly proven as lifesaving public policy actions by reducing the high crash exposure of younger teen drivers during the time when they are least able to rely on mature judgment and experience to drive safely.

Part of Advocates' approach to promoting GDL legislation has been to address the education needs of both state and federal legislators regarding the research on both GDL and driver education courses. This has greatly complicated the task because many state and federal officials (as well as parents) believe that driver education courses alone are effective, and because driver education in many school districts is a well established part of secondary school education.

\section{Public opinion polls}

One of the most successful strategies used by Advocates to counter opposition to federal and state GDL and other highway safety laws are public opinion polls. Advocates has commissioned independent pollster Lou Harris to conduct several public opinion polls over the past 10 years to assess public attitudes on a variety of issues related to highway, auto, and truck safety including teen driving.

In a public opinion poll conducted by Lou Harris for Advocates in 2001, several questions concerning some of the most controversial features of GDL laws were asked. Harris polled a cross section of 1001 US adults ( 18 years and older) on a wide range of safety issues including questions on teen driver restrictions. By large majorities, the public wants enforced restrictions placed on young drivers before and initially after they receive their licenses. The poll indicated that there is broad support for teenage drivers to complete at least 30-50 hours of practice driving accompanied by an adult (95\% support), requiring a six month learner's permit (92\% support), and limiting night-time driving as well as teen passengers (74\% support). However, when the public was surveyed about increasing the driving age above the current minimum age, a 54-42\% margin opposed the suggestion. ${ }^{27}$ At present, the minimum driving age allowed in the US varies widely between states and is considerably younger than in most industrialized nations.

\section{CURRENT AND FUTURE LEGISLATIVE AGENDA}

The model of changing driver behavior by combining education and enforcement of laws has succeeded in reducing impaired driving deaths and injuries, increasing seat belt use for adults and child restraints for children, promoting the use of motorcycle helmets, and providing a safer driving environment for inexperienced teens. Advocates will continue to pursue a strategy of legislative actions and education in its work ahead, which includes continued dedication to improving GDL requirements, seat belt laws and cell phone restrictions, and improving vehicle safety.

\section{Graduated driver licensing}

Legislation is currently pending in the 109th Congress to accelerate state adoption of GDL laws. Senator Christopher Dodd (D-CT) and Senator John Warner (R-VA) have introduced legislation, the Safe Teen and Novice Driver Uniform Protection Act of 2005 ( S 2318). This bill encourages states to adopt a comprehensive GDL law by offering incentive grant money or withholding specific amounts of federal aid highway funds from a state not in compliance. Based on the successful achievement of uniform impaired driving laws as a result of federal leadership, it is expected that passage of this bill would greatly accelerate state adoption of GDL laws to provide uniformity in all 50 states.

\section{Seat belt use and cell phone restrictions}

Advocates is also pursuing a dual strategy on the issue of increasing seat belt use. Every year, several states are identified by Advocates to aggressively pursue adoption of a primary seat belt use law. Again, because of the slow pace of enactment by state legislatures (currently, only 25 states and the District of Columbia have a primary enforcement seat belt law), Advocates is promoting federal legislation to act as a catalyst to uniform state enactment of primary enforcement seat belt laws.

Primary enforcement seat belt laws in every state will help to increase seat belt usage among teen drivers and passengers who, according to the National Highway Traffic Safety Administration (NHTSA), have lower seat belt usage rates than adults. ${ }^{2}$ Studies have shown that many high school students fail to use their safety belts even when riding with adults who are buckled up. Findings from an observational study conducted at 12 high schools found that $46 \%$ of high school students were not wearing their safety belts when riding with adult drivers. ${ }^{28}$ Furthermore, many state legislatures are also considering and 11 states have passed legislation imposing a cell phone restriction on teen drivers either based on age of the driver or possession of provisional license. These laws are additional attempts to address the issue of driver distraction for teens.

\section{Improving vehicle crashworthiness to improve safety for teens}

Another effective strategy employed by Advocates to reduce teen driving deaths and injuries is to promote actions by NHTSA to improve the crashworthiness of vehicles. Dr William Haddon, Jr, the first Administrator of NHTSA, on whose work Advocates is based, revolutionized highway safety when he discarded the fragmented attempts at addressing highway safety and replaced them with a coherent framework within which safety efforts should be organized-the Haddon matrix. ${ }^{29}{ }^{30}$ Dr Haddon recognized that the focus on driver behavior alone was not sufficient to prevent or reduce injuries. When prevention fails, driving errors are committed and crashes occur, so it is also critical to reduce crash severity and the incidence of fatalities and injuries.

In addition to programs intended to modify unsafe behaviors that contribute to crashes by teenage drivers, vehicle based countermeasures including improvements in design and technology can help prevent crashes. The marketing of small sport utility vehicles (SUVs) to young people, including the use of SUVs by teenagers, raises safety 
concerns because of the penchant of young drivers for risk taking behavior combined with the high rate of rollover of these vehicles in single vehicle crashes. ${ }^{4}{ }^{7}$ Improvements in vehicle stability brought about by electronic and rollover stability control systems or other technologies can prevent rollover crashes involving young drivers, including teenage drivers. Design improvements involving roof strength and mitigation of full and partial ejection can be effective in ameliorating injuries to occupants in rollover crashes, including teenagers.

Other means of preventing crashes involving teenage drivers includes limiting distractions from in-vehicle information and entertainment devices so they cannot function when a teen is operating the vehicle, and technologies to increase seat belt use among teens such as belt use reminders. ${ }^{23}$ Technologies that permit parental monitoring during vehicle use by teenage drivers (vehicle cameras, speed governors, etc) are also available for installation as aftermarket devices. Finally, some consideration has been given to amending state laws to increase driving age, either the age at which a driving permit is initially available or the age at which full licensure can be obtained. ${ }^{31}$

Advocates, working with a coalition of medical, health, safety, consumer, and insurance companies, successfully lobbied in support of legislation that, after a three year effort, was signed into law on 10 August 2005. The law-the Safe, Accountable, Flexible, Efficient Transportation Equity Act: A Legacy for Users (SAFETEA-LU) (Pub L 109-59, 119 STAT 1144 (Aug 10, 2005)) — sets a regulatory agenda for NHTSA actions on long overdue and critically important federal vehicle safety standards. These include statutory deadlines for rulemaking actions on safety standards addressing vehicle stability, ejection prevention, roof crush resistance, and side impact protection.

Improvements in vehicle crash avoidance and crashworthiness will benefit the entire motoring public. However, due to the overrepresentation of teens in passenger vehicle rollover crashes, improved safety standards preventing and mitigating rollover crashes will make a significant contribution to reducing teen driver and teen passenger fatalities and serious injuries.

\section{CONCLUSION}

Reducing teen driving deaths and injuries requires a comprehensive approach involving safer driving behavior and safer vehicles. Advocates continues to pursue enactment of GDL laws in state legislatures as well as promote improvements in federal motor vehicle safety standards. The slow pace in achieving uniform adoption by states of the most critical and optimal elements of a GDL law requires action by Congress to encourage and compel state action. Advocates will continue to pursue legislative strategies at both federal and state levels of government to address this serious public health problem.

\section{ACKNOWLEDGEMENTS}

The author appreciates the assistance of Gerald A Donaldson, PhD, Advocates for Highway and Auto Safety.

This paper was first presented as part of the first Expert Panel meeting of the Youthful Driver Research Initiative, a collaborative research program between the Center for Injury Research and Prevention (http://www.chop.edu/injury) at the Children's Hospital of Philadelphia (CHOP) (http://www.chop.edu) and State Farm Insurance Companies ${ }^{\circledR}$ (State Farm) (http://www.statefarm.com). The views presented in this paper are those of the author(s) and are not necessarily the views of CHOP or State Farm.

Competing interests: I have no financial position in any competing interest, and I have never received funds from private interests. I am vice president of Advocates for Highway and Auto Safety, an organization

\section{About the author}

Jacqueline S Gillan is Vice President of Advocates for Highway and Auto Safety (Advocates). She was a founding board member of the organization before joining the staff in 1990. Her 30 year professional career has been in the areas of transportation planning and government relations. She has worked in senior policy positions for three state transportation agencies (New Jersey, California, and Ohio), the US Department of Transportation and the United States Senate. She is a resource and spokesperson in the national media on highway and auto safety issues and frequently testifies before Congress and state legislatures. Ms Gillan is a graduate of the University of California at Santa Barbara and holds a master's degree in urban planning from the University of California at Los Angeles. Advocates is a coalition of consumer, health, safety, medical, and insurance companies and organizations working together to reduce highway deaths and injuries by promoting effective laws, programs and policies in state legislatures, in Congress and in the federal government.

dedicated to reducing the harm caused by motor vehicle crashes and which is supported by insurers.

\section{REFERENCES}

1 National Center for Health Statistics. Washington, DC: Centers for Disease Control, National Institutes of Health, Available at http://www.cdc.gov/nchs (accessed May 2006).

2 National Highway Traffic Safety Administration. Traffic safety facts 2005. Washington, DC: National Center for Statistics and Analysis, National Highway Traffic Safety Administration, United States Department of Transportation, February, 2006.

3 Falkmer T, Torbjorn N. A comparison of eye movement behavior of inexperienced and experienced drivers in real traffic environments. Optom Vis Sci 2005;82:732-9.

4 Gonzales M, Dickinson L, DiGiuseppi C, et al. Student drivers: a study of fatal motor vehicle crashes involving 16-year-old drivers. Annals Emer Med 2005;45:140-6.

5 Williams A. Teenage drivers' patterns of risk. J Safety Res 2003;34:5-15.

6 Doherty S, Andrey J, MacGregor C. The situational risks of young drivers: the influence of passengers, time of day and day of week on accident rates. Accid Anal Prev 1998;30:45-52.

7 Deutermann W. Characteristics of fatal rollover crashes, DOT HS 809438 Washington, DC: National Center for Statistics and Analysis, National Highway Traffic Safety Administration, United States Department of Transportation, April, 2002.

8 McCartt A, Geary L, Solomon M. Requiring seat belt use as part of a school parking permit program: does it increase students' seat belt use. Traf Inj Prev 2005;6:120-6.

9 Lin M, Fearn K. The provisional license: nighttime and passenger restrictionsa literature review. J Safety Res 2003;34:51-61.

10 Williams A. Teenage passengers in motor vehicle crashes: a summary of current research, Insurance Institute for Highway Safety. September, 2001.

11 Dee T, Grabowski D, Morrisey M. Graduated licensing and teen traffic fatalities. J Health Econ 2005;24:571-89.

12 National Center for Statistics and Analysis. Fatality Analysis Reporting System, September, 2005.

13 First International Conference on Novice Driver Issues. April 1999. An initiative of the Vehicle User Characteristics Committee of the Transportation Research Board of the National Academies. Available at http:// noviceforum.drivers.com (accessed May 2006).

14 Williams A, Mayhew R. Graduated licensing: a blueprint for north America, Insurance Institute for Highway Safety. Arlington VA. Traffic Injury Foundation, Ottawa, Ontario, Canada. August, 2004.

15 Williams A, Preusser D. Night driving restrictions for youthful drivers: a literature review and commentary. J Pub Health Pol 1997;18:2334-45.

16 Cooper D, Atkins F, Gillen D. Measuring the impact of passenger restrictions on new teenage drivers. Accid Anal Prev 2005;37:19-23.

17 National Transportation Safety Board. Most wanted transportation safety improvements - state issues, Safety Recommendation H-02-30. Washington, DC: National Transportation Safety Board, November 8, 2002.

18 Advocates for Highway and Auto Safety. Roadmap to highway safety laws. Washington, DC: Advocates for Highway and Auto Safety, Available at http://www. saferoads.org (accessed May 2006).

19 Vernik J, Li G, Gielen A. Effects of high school driver education on motor vehicle crashes, violations, and licensure. Am J Prev Med $1999 ; 16: 40-6$. 
20 Eby D, Molnar L. Matching traffic safety strategies to young characteristics: a literature review of cognitive development. Ann Arbor, MI: University of Michigan Transportation Research Institute, September, 1998.

21 Anderson S, Abdalla A, Goldberg C, et al. Young driver: a study of policies and practices - report of findings. Fairfax VA: George Mason University, December, 2000.

22 Foss R, Goodwin A. Enhancing the effectiveness of graduated-licensing legislation. J Safety Res 2003;34:79-84.

23 Wynne-Jones $\mathbf{P}$, Hurst $\mathrm{P}$. The AAA driver training evaluation. Wellington, New Zealand: Ministry of Transport, 1984.

24 Glad A. Phase 2 in the driver education effect on accident risk. Oslo, Norway: Institute of Transport Economics, 1988.

25 Katila A, Keskinene E, Laapotti S, et al. Changes in slippery road accidents as an effect of renewed driver training in finland. Turku, Finland: University of Finland, 1995.
26 Mayhew D, Simpson H. Effectiveness and role of driver education and training in a graduated licensing system. Ottawa, Ontario Canada: Traffic Injury Research Foundation, 1996.

27 Harris L. The fourth survey of attitudes of the American people on highway and auto safety. Washington, DC: Advocates for Highway and Auto Safety, September, 2001.

28 Insurance Institute for Highway Safety. Status Report, 2002;37. Arlington VA: Insurance Institute for Highway Safety, 2002.

29 Haddon W. On the escape of tigers: an ecologic note. Am J Pub Health 1970;60:2229-34.

30 Haddon W. Options for the prevention of motor vehicle crash injury. Israeli Med J 1980;16:45-65.

31 Burroughs T. Kansas House Bill 2218. Introduced 28 January 2005.

Available at http://www.kslegislature.org/bills/2006/2218.pdf (accessed May 2006). 